\title{
Recovery of renal function after long-term dialysis in hemolytic uremic syndrome
}

\author{
Brunner, Kathrin ; Bianchetti, Mario G ; Neuhaus, Thomas J
}

\begin{abstract}
Long-lasting recovery of renal function of the native kidneys after prolonged renal replacement therapy is rare. An 8-year-old girl and a 3-year-old boy had suffered from acute atypical and diarrheaassociated hemolytic uremic syndrome (HUS), respectively, with subsequent apparent end-stage renal failure. Both recovered renal function after long-lasting anuria and dialysis of 8 and 16months, respectively. After prolonged follow-up, i.e., 7 and 5years after cessation of dialysis, they attained normal or slightly reduced renal function (plasma creatinine 84 and $90 \mu \mathrm{mol} / \mathrm{l}$, respectively). In addition, growth and cognitive development were normal. We conclude that caution is appropriate before offering early renal transplantation to pediatric patients with presumed end-stage kidney disease secondary to HUS
\end{abstract}

DOI: https://doi.org/10.1007/s00467-003-1337-4

Posted at the Zurich Open Repository and Archive, University of Zurich ZORA URL: https://doi.org/10.5167/uzh-156275

Journal Article

Published Version

Originally published at:

Brunner, Kathrin; Bianchetti, Mario G; Neuhaus, Thomas J (2004). Recovery of renal function after long-term dialysis in hemolytic uremic syndrome. Pediatric Nephrology, 19(2):229-231.

DOI: https://doi.org/10.1007/s00467-003-1337-4 
Kathrin Brunner • Mario G. Bianchetti • Thomas J. Neuhaus

\section{Recovery of renal function after long-term dialysis in hemolytic uremic syndrome}

Received: 21 July 2003 / Revised: 11 September 2003 / Accepted: 11 September 2003 / Published online: 27 November 2003 (C) IPNA 2003

\begin{abstract}
Long-lasting recovery of renal function of the native kidneys after prolonged renal replacement therapy is rare. An 8-year-old girl and a 3-year-old boy had suffered from acute atypical and diarrhea-associated hemolytic uremic syndrome (HUS), respectively, with subsequent apparent end-stage renal failure. Both recovered renal function after long-lasting anuria and dialysis of 8 and 16 months, respectively. After prolonged followup, i.e., 7 and 5 years after cessation of dialysis, they attained normal or slightly reduced renal function (plasma creatinine 84 and $90 \mu \mathrm{mol} / \mathrm{l}$, respectively). In addition, growth and cognitive development were normal. We conclude that caution is appropriate before offering early renal transplantation to pediatric patients with presumed end-stage kidney disease secondary to HUS.
\end{abstract}

Keywords Hemolytic uremic syndrome $\cdot$ Renal replacement therapy $\cdot$ Recovery

\section{Introduction}

The term end-stage kidney disease is used to indicate irreversible kidney failure requiring dialysis and renal transplantation. Recovery of renal function of the native or transplanted kidneys after prolonged dialysis has rarely

K. Brunner · M. G. Bianchetti

Division of Pediatric Nephrology,

University of Bern,

Bern, Switzerland

K. Brunner · T. J. Neuhaus

Division of Pediatric Nephrology,

University of Zurich,

Zurich, Switzerland

T. J. Neuhaus ( $)$

Division of Pediatric Nephrology,

University Children's Hospital,

Steinwiesstrasse 75, 8032 Zurich, Switzerland

e-mail: thomas.neuhaus@kispi.unizh.ch

Tel.: +41-1-2667111

Fax: +41-1-2667171 been reported, and mainly in adult patients $[1,2,3,4,5,6$, $7,8,9,10]$. We report on two children with hemolytic uremic syndrome (HUS) [11] who experienced a longlasting recovery of renal function after being on dialysis for 8 and 16 months, respectively.

\section{Case reports}

Between 1970 and 2002, 130 and 67 patients underwent chronic renal replacement (i.e., necessary renal replacement therapy for more than 6 months) in Zurich and Bern, respectively. In both centers, HUS was an important cause of end-stage renal failure: 12 patients (9\%) from Zurich had HUS, two had diarrhea-related HUS and 10 atypical HUS. In Bern, HUS was the underlying cause in five $(7 \%)$ patients, one had diarrhea-related HUS and four atypical HUS. Two of the 197 patients, both with HUS, recovered renal function.

\section{Case 1}

An 8-year-old girl with a history of vomiting, fever and pallor for 10 days was referred. There was no history of diarrhea. Physical examination revealed high blood pressure $(132 / 102 \mathrm{mmHg}$ : 95 th centile for gender, age and height: 115/75), pallor and a mild scleral jaundice. Hematology showed anemia (hemoglobin $37 \mathrm{~g} / \mathrm{l}$, normal $100-150 \mathrm{~g} / \mathrm{l})$ and thrombocytopenia $\left(85 \times 10^{9} / 1\right.$, normal 200 $\left.400 \times 10^{9} / 1\right)$; a blood film demonstrated moderate red blood cell fragmentation. Blood chemistry disclosed renal failure with elevated creatinine $(399 \mu \mathrm{mol} / \mathrm{l}$, normal range for age $<66 \mu \mathrm{mol} / \mathrm{l})$ and urea $(54 \mathrm{mmol} / \mathrm{l}$, normal $<8.2 \mathrm{mmol} / \mathrm{l})$, hyperbilirubinemia (45 $\mu \mathrm{mol} / \mathrm{l}$, normal $<30 \mu \mathrm{mol} / \mathrm{l})$ and high lactate dehydrogenase $(1,360 \mathrm{U} / 1$, normal $<500 \mathrm{U} / \mathrm{l})$. Complement $\mathrm{C} 3$, factor $\mathrm{H}$ and von Willebrand cleavage protease were normal, antinuclear or antineutrophil cytoplasmic autoantibodies were not detected and the direct Coombs test was negative. Specific Escherichia coli lipopolysaccharide antibodies were not measured. Urinalysis showed hematuria, red cell casts and marked proteinuria. No E. coli strains harboring genes for shigatoxin were cultured from the stool. Hence the diagnosis of atypical (diarrhea-negative) HUS was made. A renal biopsy was not done. Within 10 days, the girl became anuric. Continuous automated peritoneal dialysis was started, amlodipine was given to treat hypertension and fresh frozen plasma was administered on 15 occasions. During the following 4 weeks she experienced focal seizures with a tendency towards generalization. Intravenous diazepam and phenytoin were given repeatedly, followed by oral carbamazepine. One month after onset of the disease the girl was switched from peritoneal dialysis to hemodi- 
alysis (three sessions per week) because of two episodes of bacterial peritonitis. She continued to be anuric.

Six months after starting dialysis, the girl reported to pass small portions of urine one to two times a week. One month later, urine production increased and hemodialysis was reduced to two weekly sessions. Eight months after onset, dialysis was finally stopped. The subsequent clinical course was uneventful.

Recently, i.e., 7 years after cessation of dialysis, the girl was well on treatment with irbesartan $300 \mathrm{mg}$ daily, chlorthalidone $25 \mathrm{mg}$ daily, and carabamazepine 1,200 mg daily. Growth (body weight: $52 \mathrm{~kg}$, height: $1.64 \mathrm{~m}$ ) and cognitive development were both normal. Renal function, as assessed as plasma creatinine (84 $\mu \mathrm{mol} / \mathrm{l}$, normal range for age $<98 \mu \mathrm{mol} / \mathrm{l}$ ) and estimated glomerular filtration rate (Schwartz formula: $78 \mathrm{ml} / \mathrm{min} / 1.73 \mathrm{~m}^{2}$ body surface area), was normal. In addition, casual blood pressure (109/50 mmHg: 95th centile: $128 / 83 \mathrm{mmHg}$ ) and 24-h ambulatory blood pressure (108/62 $\mathrm{mmHg}$ : 95th centile: $124 / 76 \mathrm{mmHg}$ ), and urinalysis (normal sediment, albumin/creatinine $3.5 \mathrm{~g} / \mathrm{mol}$ ) were normal. No further family members were suffering from HUS or renal disease.

Case 2

A 3-year-old boy presented with a 5-day history of pallor and several blue bruises. A week earlier he had suffered from watery diarrhea for 2 days after the consumption of raw cow milk. Physical examination demonstrated high blood pressure $(120 / 66 \mathrm{mmHg}$ : 95th centile: $109 / 65 \mathrm{mmHg}$ ), mild scleral jaundice and swollen eyelids. Hematology revealed anemia (hemoglobin $59 \mathrm{~g} / \mathrm{l}$ ) and thrombocytopenia $\left(123 \times 10^{9} / 1\right)$; a blood film showed marked red blood cell fragmentation. Blood chemistry disclosed mild renal failure (creatinine $103 \mu \mathrm{mol} / \mathrm{l}$, normal range for age $<51 \mu \mathrm{mol} / \mathrm{l}$; urea $14 \mathrm{mmol} / \mathrm{l})$, hyperbilirubinemia $(53 \mu \mathrm{mol} / \mathrm{l})$ and high lactate dehydrogenase (1,034 U/l). Complement C3 was normal, antinuclear or antineutrophil cytoplasmic autoantibodies were not detected and the direct Coombs test was negative. Specific E. coli antibodies were not measured. Urinalysis revealed hematuria, red cell casts and marked proteinuria. E. coli strains harboring genes for shigatoxin could not be cultured from his stool at this stage. Systolic blood pressure further increased up to $140-160 \mathrm{mmHg}$, requiring intravenous administration of dihydralazine. Several packed red cells had to be given due to persistent microangiopathic hemolytic anemia. A renal biopsy disclosed extensive lesions of thrombotic microangiopathy including both intraglomerular capillaries and extraglomerular arterioles and small arteries. Urinary output decreased and the boy became anuric. Despite the unusual course-slow progression of renal failure over 3 weeks-a presumptive diagnosis of diarrhea-positive HUS was made.

Hemodialysis had to be started 18 days after admission. In addition, plasma exchange with albumin and an infusion of fresh frozen plasma at the end of each session was applied on 12 occasions. As renal function did not improve, plasma exchange was stopped and the patient switched to automated peritoneal dialysis (duration: $12 \mathrm{~h}$ during the night; filling volume: $40 \mathrm{ml} / \mathrm{kg}$ body weight: number of exchanges: 12/night). Blood pressure control was only achieved with a triple therapy of atenolol, nifedipine and minoxidil.

After being on a constant peritoneal dialysis regimen for 14 months, the boy started to pass urine. Firstly, there were only small volumes once a week, but urine output increased steadily. Finally, 16 months after onset of renal replacement therapy, peritoneal dialysis was ceased.

Recently, i.e., 5 years after cessation of dialysis, the boy was in good health. Growth (body weight: $28 \mathrm{~kg}$, height: $1.31 \mathrm{~m}$ ) and cognitive development were both normal. Renal function, as assessed as plasma creatinine $(90 \mu \mathrm{mol} / \mathrm{l}$, normal range for age $<75 \mu \mathrm{mol} / \mathrm{l}$ ) and estimated glomerular filtration rate (Schwartz formula: $58 \mathrm{ml} / \mathrm{min} / 1.73 \mathrm{~m}^{2}$ body surface area), was slightly reduced. There was mild microhematuria, but no proteinuria. Despite antihypertensive treatment with valsartane and amlodipine (20 and $7.5 \mathrm{mg}$ daily, respectively), blood pressure (casual: 127/
$83 \mathrm{mmHg}$; 24-h ambulatory: 128/83 $\mathrm{mmHg}$ ) remained persistently above the 95th centile (casual: 116/77; 24-h: 117/75). Echocardiography and fundoscopy were normal. No further family members were suffering from HUS or renal disease.

\section{Discussion}

We report long-lasting recovery of renal function after prolonged dialysis, i.e., more than 6 months, in pediatric hemolytic uremic syndrome. The term end-stage kidney disease denotes irreversible deterioration of renal function. A few patients, mainly adults, have been reported to regain independent renal function of their native kidneys after long-term dialysis [1, 2, 3, 4, 5, 7, 8, 9]. Recovery mostly occurred within 6-12 months of initiating renal replacement therapy and was generally partial, both related to glomerular and tubular function. In addition, recovery appeared to be more common in kidney diseases secondary to treatable malignancies, adverse effects of drugs as reported in two cases of atypical HUS [2, 4] or in hypertensive kidney disease $[1,9]$.

Recovery after long-term dialysis has occasionally been reported in children $[6,10]$ : The duration of renal replacement therapy had lasted less than 1 year in the majority of these children. In addition, the recovery was transient and lasted less than 1 year in the majority of patients.

Which protective factors might have contributed to the favorable outcome in our patients with HUS are not clear, especially as two main risk factors of bad outcome in HUS [12]-long-term anuria in both patients and extensive thrombotic microangiopathy in one-were present. In particular, atypical HUS carries a substantial risk for end-stage renal failure and is an important cause of endstage renal failure in childhood [11]. The high risk of recurrence-associated with high morbidity and mortality-has prompted some centers, including our own, to avoid early renal transplantation in those children.

In conclusion the present report suggests that caution is appropriate before offering early renal transplantation to pediatric patients with presumed end-stage kidney disease secondary to diarrhea-associated or atypical HUS.

\section{References}

1. Nunan TO, Stevens EA, Croft DN, Hilton PJ, Jones NF, Wing AJ (1983) Recovery of renal function after prolonged dialysis and transplantation. BMJ 287:248-249

2. Verwey J, Boven E, van der Meulen J, Pinedo HM (1984) Recovery from mitomycin C-induced hemolytic uremic syndrome. Cancer 54:2878-2881

3. Hansen BL, Birkeland SA (1985) Recovery of kidney function after cessation of graft function or prolonged dialysis treatment. Scand J Urol Nephrol 19:217-219

4. Ortega Marcos O, Escuin F, Miguel JL, Gomez Fernandez P, Perez Fontan M, Selgas R, Sanchez Sicilia L (1985) Hemolytic uremic syndrome in a patient with gastric adenocarcinoma: partial recovery of renal function after gastrectomy. Clin Nephrol 24:265-268 
5. Sekkarie MA, Port FK, Wolfe RA, Guire K, Humphrys R, Van Amburg G, Ferguson CW (1990) Recovery from end-stage renal disease. Am J Kidney Dis 15:61-65

6. Ehrich JH, Rizzoni G, Brunner FP, Brynger H, Geerlings W, Fassbinder W, Raine AE, Selwood NH, Tufveson G (1989) Combined report on regular dialysis and transplantation of children in Europe. Nephrol Dial Transplant 6 (Suppl 1):37-47

7. Lindblad AS, Nolph KD (1992) Recovery of renal function in continuous ambulatory peritoneal dialysis: a study of National CAPD Registry data. Perit Dial Int 12:43-47

8. Rottembourg J (1993) Residual renal function and recovery of renal function in patients treated by CAPD. Kidney Int Suppl 40:S106-S110

9. James SH, Meyers AM, Milne FJ, Reinach SG (1995) Partial recovery of renal function in black patients with apparent end- stage renal failure due to primary malignant hypertension. Nephron 71:29-34

10. Kaplan BS, Garcia CD, Chesney RW, Segar WE, Giugno K, Chem R (2000) Peripheral gangrene complicating idiopathic and recessive hemolytic uremic syndromes. Pediatr Nephrol 14:985-989

11. Neuhaus TJ, Calonder S, Leumann EP (1997) Heterogeneity of atypical haemolytic uraemic syndromes. Arch Dis Child 76:518-521

12. Habib R, Levy M, Gagnadoux MF, Broyer M (1982) Prognosis of hemolytic uremic syndrome in children. Adv Nephrol 11:99128 